\title{
Surgical unroofing of hemodynamically significant myocardial bridges in a pediatric population
}

Katsuhide Maeda, MD, PhD, ${ }^{\mathrm{a}}$ Ingela Schnittger, MD, ${ }^{\mathrm{b}}$ Daniel J. Murphy, MD, ${ }^{\mathrm{b}}$ Jennifer A. Tremmel, MD, ${ }^{\mathrm{b}}$ Jack H. Boyd, MD, ${ }^{\mathrm{a}}$ Lynn Peng, MD, ${ }^{\mathrm{c}}$ Kozo Okada, MD, ${ }^{\mathrm{b}}$ Vedant S. Pargaonkar, MD, ${ }^{\mathrm{b}}$ Frank L. Hanley, MD, ${ }^{a}$ Robert Scott Mitchell, MD, ${ }^{a}$ and Ian S. Rogers, $\mathrm{MD}^{\mathrm{b}}$

\section{ABSTRACT}

Background: Although myocardial bridges (MBs) are traditionally regarded as incidental findings, it has been reported that adult patients with symptomatic MBs refractory to medical therapy benefit from unroofing. However, there is limited literature in the pediatric population. The aim of our study was to evaluate the indications and outcomes for unroofing in pediatric patients.

Methods: We retrospectively reviewed all pediatric patients with MB in our institution who underwent surgical relief. Clinical characteristics, relevant diagnostic data, intraoperative findings, and postoperative outcomes were evaluated.

Results: Between 2012 and 2016, 14 pediatric patients underwent surgical unroofing of left anterior descending artery MBs. Thirteen patients had anginal symptoms refractory to medical therapy, and 1 patient was asymptomatic until experiencing aborted sudden cardiac arrest during exercise. Thirteen patients underwent exercise stress echocardiography, all of which showed mid-septal dyssynergy. Coronary computed tomography imaging confirmed the presence of $\mathrm{MBs}$ in all patients. Intravascular ultrasound imaging confirmed the length of MBs: $28.2 \pm 16.3 \mathrm{~mm}$, halo thickness: $0.59 \pm 0.24 \mathrm{~mm}$, and compression of left anterior descending artery at resting heart rate: $33.0 \pm 11.6 \%$. Invasive hemodynamic assessment with dobutamine confirmed the physiologic significance of the MBs with diastolic fractional flow reserve: $0.59 \pm 0.13$. Unroofing was performed with the patient under cardiopulmonary bypass (CPB) in the initial 9 cases and without CPB in the subsequent 5 cases. All patients were discharged without complications. The 13 symptomatic patients reported resolution of symptoms on follow-up, and improvement in symptoms and quality of life was documented using the Seattle Angina Questionnaire version 7.

Conclusions: Unroofing of MBs can be safely performed in pediatric patients, with or without use of CPB. In symptomatic patients, unroofing can provide relief of symptoms refractory to medical therapy. (J Thorac Cardiovasc Surg 2018;156:1618-26)

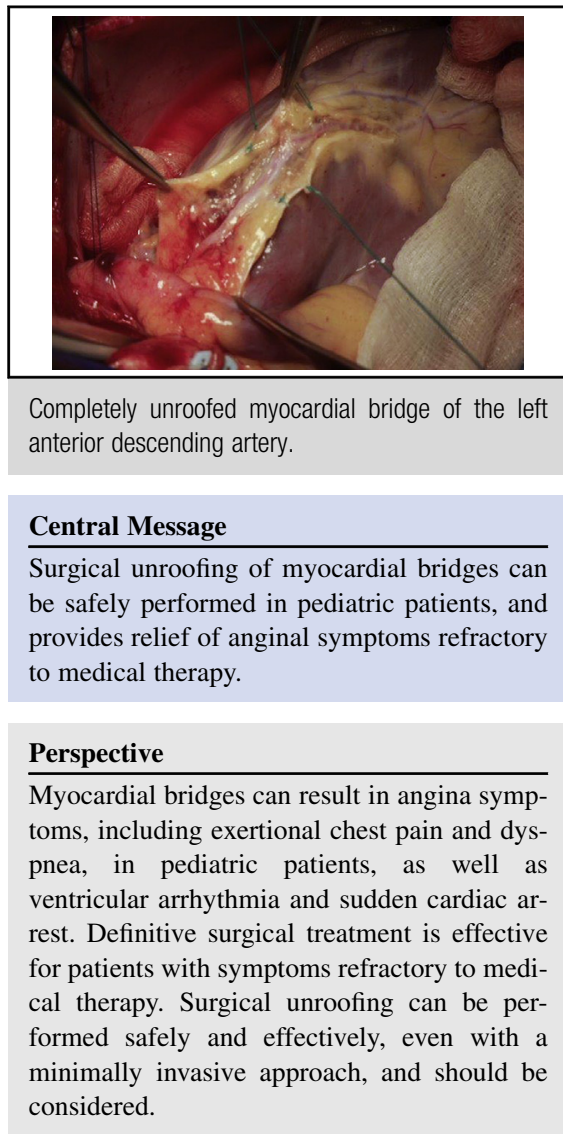

See Editorial Commentary page 1627

See Editorial page 1617.
From the Departments of ${ }^{\mathrm{a}}$ Cardiothoracic Surgery, ${ }^{\mathrm{b}} \mathrm{Cardiovascular}$ Medicine, and ${ }^{\mathrm{c}}$ Pediatric Cardiology, Stanford University, Stanford, Calif.

Read at the 97th Annual Meeting of The American Association for Thoracic Surgery, Boston, Massachusetts, April 29-May 3, 2017.

Received for publication May 15, 2017; revisions received Dec 22, 2017; accepted for publication Jan 9, 2018; available ahead of print July 11, 2018.

Address for reprints: Katsuhide Maeda, MD, PhD, Division of Pediatric Cardiac Surgery, Department of Cardiothoracic Surgery, Stanford University Medical Center, Falk Cardiovascular Research Center, 300 Pasteur Dr, Stanford, CA 94305-5407 (E-mail: kmaeda@stanford.edu).

$0022-5223 / \$ 36.00$

Copyright (c) 2018 by The American Association for Thoracic Surgery

https://doi.org/10.1016/j.jtcvs.2018.01.081
Myocardial bridges (MBs) have been known for centuries, with their first description traced back to 1737 by Reyman in Bibliotheca Anatomica. ${ }^{1}$ In a patient with MB, a segment of a coronary artery, usually the left anterior descending

Scanning this QR code will take you to the article title page. To view the AATS Annual Meeting Webcast, see the URL next to the webcast thumbnail.

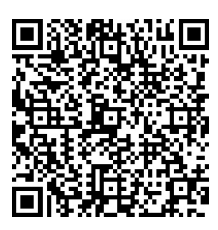



Abbreviations and Acronyms
$\mathrm{CT}=$ computed tomography
$\mathrm{dFFR}=$ diastolic fractional flow reserve
IVUS $=$ intravascular ultrasound
LAD $=$ left anterior descending artery
$\mathrm{MB}=$ myocardial bridge
MICS $=$ minimally invasive cardiac surgery
$\mathrm{SAQ}=$ Seattle Angina Questionnaire version 7

artery (LAD), takes an intramuscular course and is surrounded by myocardium for varying degrees of length and depth. They are a common anatomic finding, with prevalence reported to range from $5 \%$ to $86 \%$ using various imaging modalities and in autopsy series, yet generally accepted to have a prevalence of approximately $25 \%{ }^{2}$ Because of this common prevalence, MBs have traditionally been considered to be a largely benign condition. However, more recent literature, mostly in adults, has shown that MBs might be responsible for myocardial ischemia, ${ }^{3}$ acute coronary syndromes, ${ }^{4}$ left ventricular dysfunction, ${ }^{5}$ arrhythmias, ${ }^{6}$ and sudden cardiac arrest. ${ }^{7}$ Even in the pediatric population, symptomatic MBs have also been associated with sudden cardiac arrest. ${ }^{8,9}$

The diagnostic modalities for MB have advanced in recent years. The diagnosis of MB consists of 2 components: anatomical diagnosis and physiologic assessment. As previously mentioned, the anatomic presence of an $\mathrm{MB}$ is common, and likely most of them are asymptomatic. Although MBs can be seen on traditional invasive coronary angiography (a systolic narrowing, or "milking"), the sensitivity of this modality is low, generally estimated as approximately $5 \%$, with ranges in previous studies between $0.5 \%$ and $12 \% .^{10,11}$ Our group has shown that stress echocardiography might serve as a screening modality for the noninvasive anatomic diagnosis in symptomatic patients. ${ }^{12}$ However, a precise anatomical assessment can be made noninvasively using coronary computed tomography $(\mathrm{CT})^{13}$ because of its unique ability to noninvasively visualize the coronary arteries, the myocardium, and the relationship between these structures, and invasively using intravascular ultrasound (IVUS) imaging, on which MBs are characterized as an echolucent "half-moon" area immediately adjacent to the lumen throughout the cardiac cycle. ${ }^{14}$

In addition to the anatomical diagnosis, physiological or functional assessment of the MB is essential to confirm the clinical significance. Stress echocardiography and imaging stress tests, such as single-photon emission CT myocardial perfusion imaging, established for the detection of myocardial ischemia secondary to obstructive coronary artery disease in the practice of adult cardiology, have been shown to have a very low sensitivity for the detection of ischemia from MBs, ${ }^{15}$ likely secondary to the dynamic nature of ischemia from MBs. However, intracoronary hemodynamic assessment with Doppler and diastolic fractional flow reserve (dFFR) quantification with dobutamine stress has been shown to be instrumental in the physiological assessment of MBs. ${ }^{16,17}$

The management of symptomatic MB patient usually starts with medical treatment. The first line of medical treatment is $\beta$-blockers, ${ }^{16}$ followed by calcium channel blockers, ${ }^{18}$ with the goal of reducing peak exertional heart rate, thereby reducing compression and increasing the diastolic filling time of the coronary artery by the surrounding muscle. However, no randomized clinical trial data exist in the literature regarding options for medical therapy. The use of nitrates might conversely accentuate systolic compression of MBs, leading to an increase in symptoms. ${ }^{19}$ Because MBs are an anatomical abnormality with functional impairment of coronary flow reserve, medical treatment is essentially palliative, and cessation of the therapy typically results in return of the symptoms. In the pediatric population, the reduction in quality of life from exercise limitation, incomplete relief from medical therapy, and side effects from medical therapy, can be significant.

For refractory symptoms despite medical therapy, surgical unroofing can provide significant relief from symptoms. Although noninvasive percutaneous coronary intervention with stent placement would seem more ideal, it has been reported to have a high incidence of adverse events such as stent fractures from unabated compression. ${ }^{20}$ As such, stent placement within an $\mathrm{MB}$ should be avoided whenever possible. In adult patients, coronary artery bypass graft surgery distal to the MB segment has been reported. ${ }^{21}$ However, graft failure rates in the long term are high because of competitive flow, because the bridged native LAD is dynamically compressed yet remains patent. ${ }^{22}$ However, unroofing, myotomy of the $\mathrm{MB}$, is a definitive anatomical correction and has been shown to reduce or eliminate symptoms and increase coronary flow. ${ }^{23-25}$ In this report, we describe the surgical technique in pediatric patients with $\mathrm{MB}$, as well as their evaluation and symptomatic outcome.

\section{METHODS}

\section{Study Population}

We became aware of MBs as a potential etiology of chest pain in the pediatric population in 2012. Between September 2012 and December 2016, 14 pediatric patients younger than 21 years of age, with isolated, symptomatic, and hemodynamically significant LAD MBs underwent surgical unroofing of LAD MBs. Patients who had concomitant anomalous origin of the coronary arteries were excluded from this analysis. Each of these patients reported persistent symptoms and underwent systematic noninvasive and invasive evaluation. The detailed diagnostic algorithm is described in our previous report. ${ }^{25}$ After exercise stress echocardiography suggestive of an MB, coronary CT imaging was then obtained to confirm the presence of the MB and to evaluate the anatomic characteristics. Medical therapy was then instituted, and escalated as tolerated. If symptoms persisted 
despite maximal medical therapy, we performed invasive testing to confirm the anatomic characteristics and establish hemodynamic significance before consideration of surgical unroofing. This study was granted institutional review board approval: 24299 .

Invasive angiography and IVUS (Atlantis SR Pro2 40-MHz mechanical transducer ultrasound catheter; Boston Scientific, Marlborough, Mass) was performed on all patients to measure systolic arterial compression (defined as the change in vessel area during the cardiac cycle divided by vessel area during diastole), MB thickness (defined by the maximal thickness of the echolucent halo), relationship to septal and adjacent diagonal branches, and the maximal plaque burden (measured as the difference between vessel and lumen areas divided by vessel area with the largest plaque burden) upstream from the MB entrance (Figure 1). After IVUS, we evaluated the hemodynamic significance of the MB, measuring the dFFR (the fraction of diastolic coronary artery pressure divided by diastolic aortic pressure) and Doppler flow velocity using a Combowire (Volcano, San Diego, Calif) in the LAD. Both measurements were obtained proximal to, within, and distal to the MB at rest and during stress, which was induced by incremental intravenous infusions up to $50 \mu \mathrm{g} / \mathrm{kg} / \mathrm{min}$ dobutamine, to achieve $85 \%$ of maximum heart rate for age. We considered a dFFR of 0.76 or less as hemodynamically significant.

\section{Seattle Angina Questionnaire}

The Seattle Angina Questionnaire version 7 (SAQ) was obtained from patients at the last office visit before surgery, sometimes with the help of the parents. The questionnaire was repeated approximately 6 months after surgery. Postoperative scores were compared with preoperative scores. The SAQ is a validated, self-administered questionnaire, which classifies 5 dimensions of functional status including physical limitation due to angina, angina stability, angina frequency, treatment satisfaction, and quality of life. ${ }^{26}$ Institutional review board approval was obtained for the preoperative and postoperative SAQs. Standard informed consent was obtained additionally before all procedures.

\section{Surgical Technique}

The surgical technique for unroofing of MBs in a pediatric population follows the adult unroofing technique described in our previous report. ${ }^{25}$ Initially, several cases were performed by an adult coronary surgeon or as a combined case by an adult coronary surgeon and a pediatric cardiothoracic surgeon. Subsequent cases were performed by a pediatric cardiothoracic surgeon. The critical part of the surgery is to perform a complete unroofing of the $\mathrm{MB}$, which includes not only resecting the myocardium over the entire length of the $\mathrm{MB}$, but also making sure the artery is free on the lateral sides of the vessel. In our adult case series, we had 1 patient with refractory angina after unroofing surgery who underwent reunroofing of the MB because of an incomplete unroofing of the artery.

The surgical techniques in pediatric patients evolved at our institution over the study period, initially with full sternotomy with the patient on cardiopulmonary bypass and cardioplegic arrest, then to full sternotomy without the use of cardiopulmonary bypass, and most recently to a minimally invasive cardiac surgery (MICS) using a sternum-preserving transxiphoid approach without the use of cardiopulmonary bypass. For the MICS approach, an approximate 6-cm incision was placed over the xiphoid process. The xiphoid and lower one-third of the sternum were divided. The pericardium was opened longitudinally and the heart was positioned to expose the anterior surface of the heart using stay sutures on the pericardium and sponges on the back of the heart. For cases performed without the use of cardiopulmonary bypass, an Octopus stabilizer (Medtronic, Dublin, Ireland) was applied for stabilization.

The LAD was identified on the epicardial surface of the heart, where it entered and exited the MB proximally and distally. An "IVUS map" of the LAD (Figure 1), created before the surgery and correlated with CT images, was used to note the relationship of the MB to diagonal and septal branches of the coronary artery. After obtaining stable exposure of the LAD, using a Beaver blade, the muscle and the fat overlying the LAD was carefully resected. After resecting the overlying muscle, care was made to dissect out the coronary artery completely and detach the artery completely from
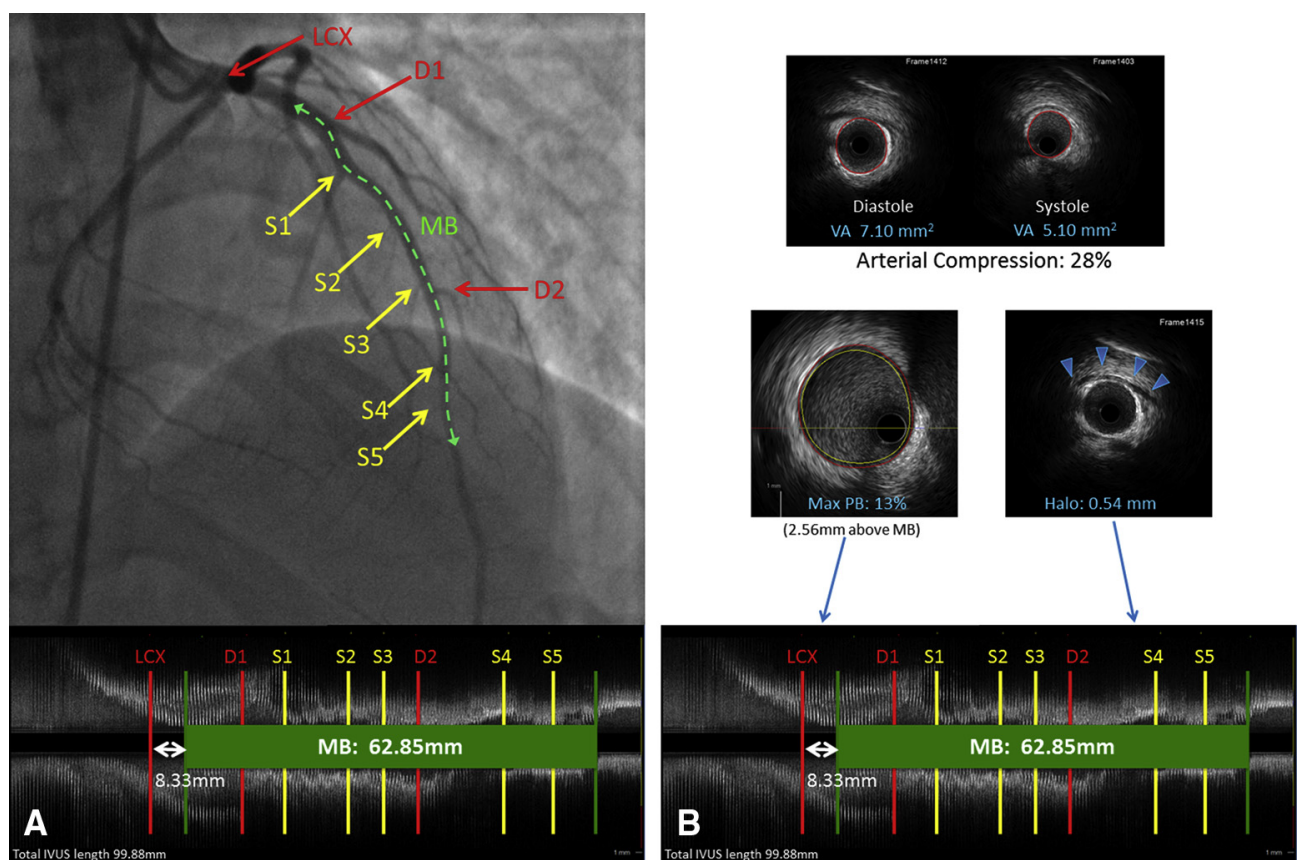

FIGURE 1. A, Coronary angiography of left anterior descending artery (LAD) with a myocardial bridge (MB). The MB is identified by the green dotted line. S1 to S5 are septal branches; D1 and D2 are the diagonal branches. The lower panels show the entire distance of the intravascular ultrasound (IVUS). B, Examples of arterial compression, maximum plaque burden (Max PB), and halo thickness on IVUS. LCX, Left circumflex artery. 
TABLE 1. Characteristics of patients who underwent unroofing of LAD MBs $(n=14)$

\begin{tabular}{lc}
\hline \multicolumn{1}{c}{ Characteristic } & Value \\
\hline Sex & \\
Male & $8(57.1)$ \\
Female & $6(42.8)$ \\
Age, $y$ & $15.6 \pm 2.4(11-20)$ \\
Body size & \\
Weight, kg & $61.8 \pm 10.7(46.2-77.0)$ \\
Height, cm & $166.4 \pm 8.2(150-180)$ \\
Family history & $6(50.0)$ \\
Symptoms & $13(92.8)$ \\
Refractory chest pain & $2(16.6)$ \\
Syncope & $1(8.3)$ \\
Sudden cardiac arrest & \\
Medical history & $1(8.3)$ \\
CoA with sub-Ao memb & $1(8.3)$ \\
Kawasaki & $1(8.3)$ \\
ICD placement & $1(8.3)$ \\
Inducible Vf &
\end{tabular}

Values are presented as $\mathrm{n}(\%)$ or mean $\pm \mathrm{SD}$ (range). CoA, Coarctation of the aorta; Ao memb, subaortic membrane; ICD, implantable cardioverter defibrillator; $V f$, ventricular fibrillation.

muscle on both sides. Because the right ventricular myocardium is relatively thin compared with the left ventricular muscle, special attention was also made to avoid entering the right ventricular wall. At the end of the resection, the operating surgeon and the referring cardiologist confirmed the complete division of all myocardial fibers crossing the LAD and confirmed that the length of the unroofed artery correlated with the length of the MB according to IVUS and CT imaging.

\section{Statistical Analysis}

Results are expressed as mean \pm SD for parametric data. Wilcoxson signed rank test was used for nonparametric data to analyze pre- and postoperative SAQ results. A $P$ value of $<.05$ was considered significant.

\section{RESULTS}

\section{Patients Demographic Characteristics}

The demographic characteristics of the patients are listed in Table 1. Eight of 14 patients were male, the age ranged from 11 to 20 years old. Thirteen patients had anginal symptoms refractory to maximized medical therapy. Two of these patients experienced previous syncope, 1 of whom had inducible ventricular arrhythmia on electrophysiology study. One patient was previously treated for Kawasaki disease, though was without sequelae. One patient had previously undergone successful surgical repair of subaortic membrane and aortic coarctation. Interestingly, 6 patients had family history (siblings) of symptomatic MB. One remaining patient, a 14-year-old boy, was asymptomatic until experiencing aborted sudden cardiac arrest during a competitive basketball game. After the MB diagnosis was confirmed and physiologic significance established according to $\mathrm{dFFR}$, unroofing surgery was performed during the
TABLE 2. Anatomic and physiologic diagnostic test results of patients who underwent unroofing of LAD MBs

\begin{tabular}{lc}
\hline \multicolumn{1}{c}{ Test } & Value \\
\hline $\begin{array}{l}\text { Stress echocardiography* } \\
\quad \text { Septal buckling }\end{array}$ & $13(100)$ \\
\hline $\begin{array}{l}\text { Coronary CT angiography } \\
\quad \text { Confirmation of MB }\end{array}$ & $14(100)$ \\
\hline $\begin{array}{l}\text { Intravascular ultrasonography } \\
\quad \text { Halo thickness, mm }\end{array}$ & $0.59 \pm 0.24$ \\
$\quad$ Compression, \% & $33.0 \pm 11.6$ \\
$\quad$ Length of MB, mm & $28.2 \pm 16.3$ \\
$\quad$ Plaque burden & $18.5 \pm 4.9$ \\
\hline $\begin{array}{l}\text { Stress hemodynamic study } \\
\quad \text { dFFR }\end{array}$ & $0.59 \pm 0.13$ \\
\hline $\begin{array}{l}\text { Values are presented as n (\%) or mean } \pm \text { SD. } C T \text {, Computed tomography; } M B \\
\text { myocardial bridge; } d F F R, \text { diastolic fractional flow reserve. }{ }^{*} \text { We did not perform }\end{array}$ \\
stress echocardiography on 1 patient with recent cardiac arrest.
\end{tabular}

same admission without attempted medical therapy because of the potentially fatal manifestation of the MB.

\section{Diagnostic Characteristics}

Table 2 shows the diagnostic, anatomic, and physiologic characteristics of the patients. Stress echocardiography was performed in all patients except 1 who had the previous sudden cardiac arrest. All patients showed septal dys-synergy with apical sparing. CT angiography confirmed the presence of the MB in all 14 patients. IVUS confirmed the length of MBs: $28.2 \pm 16.3 \mathrm{~mm}$, halo thickness: $0.59 \pm 0.24 \mathrm{~mm}$, compression at resting heart rate: $33 \pm 11.6 \%$, and number of jailed sepal branches: $2.9 \pm 1.8$. The proximal maximum plaque burden was $18.5 \pm 4.9$. The stress hemodynamic data revealed an abnormal dFFR, $0.59 \pm 0.13$, indicating hemodynamic significance.

\section{Surgical Results}

All patients underwent surgeries without any major complications. The first 9 cases were performed using a full median sternotomy with the patient on cardiopulmonary bypass and cardioplegic arrest. Five of these patients underwent homologous transfusion. One patient developed bleeding from the right ventricular wall at the time of weaning off bypass, which was repaired by 1 pledgeted suture without causing any coronary obstruction. The next 3 cases were performed using a full median sternotomy without cardiopulmonary bypass, and the most recent 2 cases were performed with a small transxiphoid sternumpreserving approach without the use of cardiopulmonary bypass. None of the 5 cases performed without cardiopulmonary bypass required homologous transfusion (Figure 2).

All patients were extubated within 24 hours and all patients were discharged without major complications within 5 days, with average hospital stay after surgery of 3.5 days. 

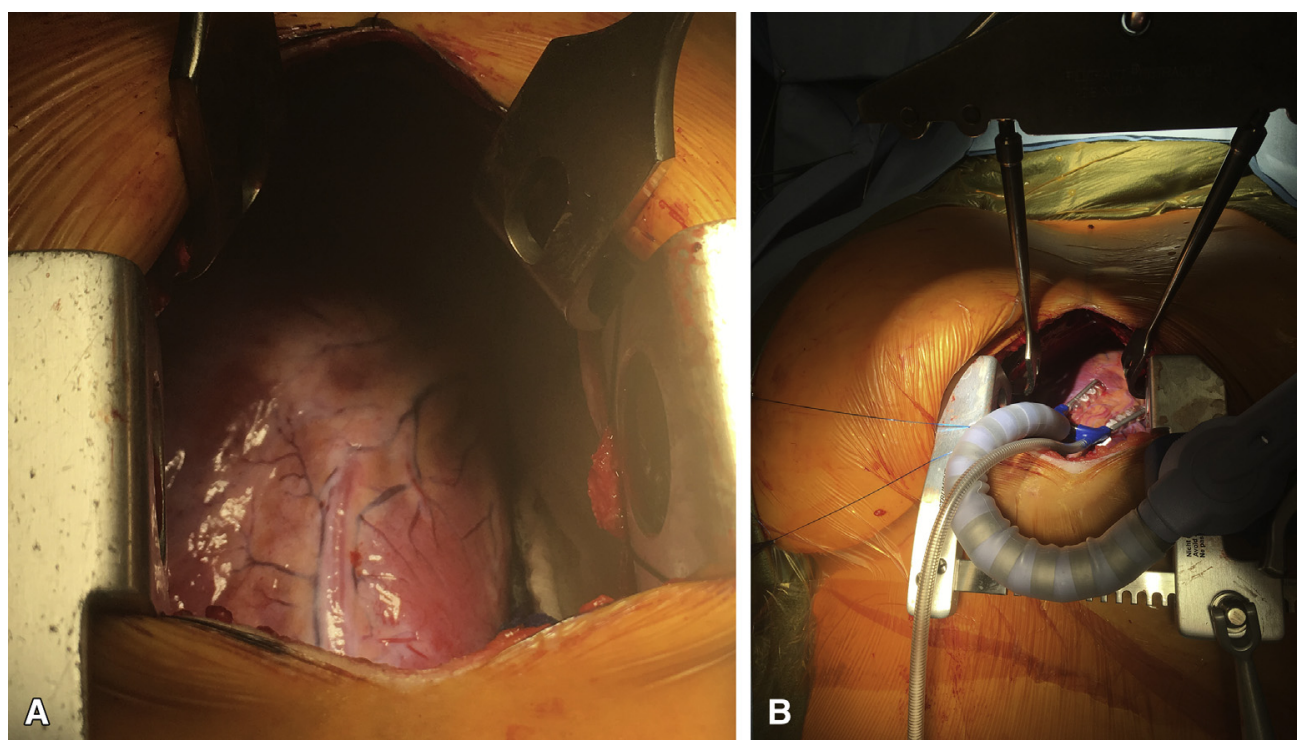

FIGURE 2. A, Intraoperative picture showing myocardial bridges of the left anterior descending artery. B, Minimally invasive cardiac surgery using the transxiphoid approach.

We did not routinely administer nitroglycerin, antiplatelet agents, or heparin postoperatively. The 13 patients with anginal symptoms reported resolution of symptoms at their discharge follow-up visit. One of the 13 patients, who was 17 years old at the time of surgery, reported transient recurrent exertional chest pain approximately 4 years after unroofing, which self-resolved and has not recurred. Repeat invasive assessment in this patient showed no IVUS evidence of residual MB and normalization of dFFR, however did show evidence of mild endothelial dysfunction after the intracoronary administration of acetylcholine during vascular function testing. The patient with inducible ventricular arrhythmia was no longer inducible in a repeat postoperative electrophysiology study. The patient who underwent unroofing after sudden cardiac arrest has had no further major adverse cardiac events.

\section{SAQ Result}

Of the total 14 patients, preoperative and postoperative SAQ scores were available for 8 patients (see the table in Figure 3). Postoperative follow-up for the questionnaire was 6.4 (range, 6.2-7.4) months. In all 5 categories (physical limitation due to angina, angina stability, angina frequency, treatment satisfaction, quality of life), statistically significant improvements were observed.

\section{DISCUSSION}

To our knowledge, this is the largest experience of pediatric patients with solitary MBs who underwent unroofing surgeries published to date. There is very limited literature available regarding surgical treatment of pediatric patients with significant MBs. It is known that MBs can be seen in children with hypertrophic cardiomyopathy and Downar and colleagues reported 5 symptomatic patients with hypertrophic cardiomyopathy and myocardial bridging of the LAD. ${ }^{27}$ All patients underwent unroofing of the MBs and reported resolution of their symptoms. In terms of solitary LAD MBs, Seki and colleagues reported successful MB unroofing in a 34-month-old 16.4-kg boy with significant left ventricular dysfunction (left ventricular ejection fraction $24 \%$ ) and mitral valve regurgitation. They reported the remarkable improvement of the left ventricular function and mitral valve regurgitation. ${ }^{28}$ Chest pain is common in the pediatric population and is more likely to be from a noncardiac etiology, particularly when transient. On the basis of our experience, however, an MB should be considered in the differential diagnosis of patients with recurrent exertional chest pain, dyspnea, and/or syncope.

Boyd and colleagues have reported on the largest adult MB surgical experience. ${ }^{25}$ This analysis showed significant improvements in all 5 dimensions of the SAQ and there were no major complications or deaths. This patient population was much older than our pediatric population, with most patients older than 40 years. Interestingly, in invasive assessment, there was not much difference between the adult and pediatric populations in terms of halo thickness, compression, length of MBs, or dFFR. Maximum plaque burden was greater in adults (adult $33.9 \pm 14.3 \%$ vs pediatric $18.5 \pm 4.9 \%$ ), suggesting that age is an important factor for progressive plaque burden. ${ }^{29}$ However, the fact that plaque was present at all on IVUS in all of our pediatric patients approximately $2 \mathrm{~cm}$ upstream of the their bridges was a disconcerting finding at such a young age. This observation supports previous observations that the hemodynamic disturbance from myocardial bridging seems to promote plaque formation proximal to the bridge, and that plaque 
Median follow up $=6.4(6.2-7.4)$ months

\begin{tabular}{|c|c|c|c|}
\hline Category & Pre-op & Post-op & P value \\
\hline Physical limitation due to \\
angina & $56.9(42.4-64.9)$ & $95.8(85.4-100)$ & .014 \\
\hline Anginal stability & $12.5(0-43.7)$ & $91.3(50-100)$ & .033 \\
\hline Anginal frequency & $60(50-85)$ & $95(90-100)$ & .015 \\
\hline Treatment satisfaction & $71.8(53.1-95.3)$ & 100 & .023 \\
\hline Quality of life & $29.2(25-41.7)$ & $95.8(87.5-100)$ & .014 \\
\hline
\end{tabular}

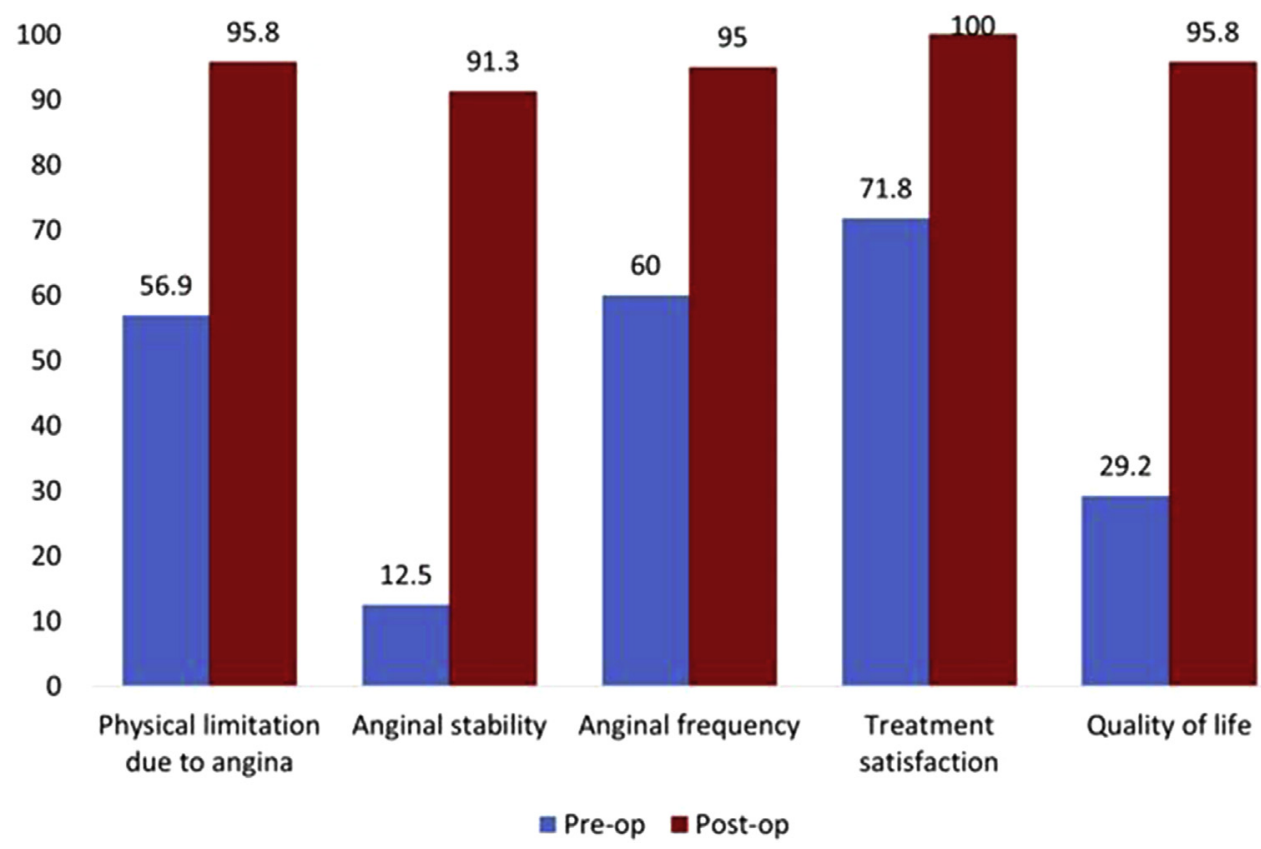

FIGURE 3. The results of the Seattle Angina Questionnaire version 7. Pre-op, Preoperative; Post-op, postoperative.

in the LAD proximal to MBs might be more prone to rupture, potentially predisposing to myocardial infarction at a younger age. ${ }^{30}$

Although our adult ${ }^{25}$ and pediatric populations showed significant improvements in all 5 dimensions of the SAQ, the improvements were even more significant in the pediatric population. This comparison of objective findings support our anecdotal observation that younger patients tend to have the greatest improvement in symptoms after unroofing. Although many factors might account for this difference, an association between myocardial bridging and endothelial dysfunction has been observed by our group and others. ${ }^{31-33}$ With cumulative duration of coronary compression from myocardial bridging serving as a potential risk factor for the development and progression of endothelial dysfunction, it seems reasonable to postulate that the greater improvement in the pediatric population might be secondary to less residual endothelial dysfunction after unroofing.

Although relief from refractory anginal symptoms was the indication for surgical referral for 13 of 14 patients in this study, the patient with refractory anginal symptoms who also experienced syncope and had inducible ventricular arrhythmia, which was no longer inducible after unroofing, and the patient who experienced aborted sudden cardiac arrest, does provide some tangible evidence that 
the dynamic ischemia from MBs might not be universally benign. Similar concerns have been observed by other investigators. ${ }^{8,9,34}$ Although coronary anomalies as a risk factor for sudden cardiac arrest in the young largely focuses on ostial coronary anomalies, particularly anomalous left coronary artery from the right sinus of Valsalva with an interarterial intramural course, MBs were also noted as associated with sudden cardiac arrest, albeit less commonly, in the larger cohort studies in young athletes and military recruits, which raised awareness of the risk with ostial coronary anomalies. ${ }^{35-37}$ The patients with refractory anginal symptoms in our cohort were not exercise-restricted over the time course of their evaluation and management before surgery because the association with sudden cardiac arrest is less common, although further consideration might be necessary as to whether exercise restriction should be considered in certain young, symptomatic patients.

In our adult population, the threshold for surgical referral is persistent anginal symptoms despite maximal medical therapy, however, a lower threshold for referral for MB unroofing might be reasonable to consider in pediatric patients. Decision analysis by Mery and colleagues favors surgical repair as the optimal strategy for patients younger than age 30 years with anomalous left coronary artery from the right sinus of Valsalva and for patients younger than the age of 25 years with anomalous right coronary artery from the left sinus of Valsalva to reduce the risk of sudden cardiac $^{\text {arrest }}{ }^{38}$ perhaps implying a "survival advantage" to diagnoses made for patients older than these ages. As such, there might be similarly greater implications to development of ischemic symptoms from MBs in the young. In addition to the aforementioned considerations regarding plaque formation, development of endothelial dysfunction, and potential risk of ventricular arrhythmia and/or sudden cardiac arrest, the cumulative reduction in quality of life, along with its associated psychological and financial burdens, from exercise limitation, long-term need for adherence to medical therapy, and side effects from medical therapy might be significant.

Unroofing surgery can be performed with a relatively low risk and short hospitalization. In our case series, our surgical technique has advanced over time from full sternotomy, cardioplegic arrest to off -bypass MICS. With the help of certain MICS techniques and instruments, stable exposure can be obtained. In our case series, a mini transxyphoid approach was chosen. Although mini left thoracotomy can be an alternative approach with the potential for better exposure, previous concerns from other investigators regarding the potential for alteration in breast and chest wall development after thoracotomy in pediatric patients suggest that careful patient selection should be considered before a left thoracotomy approach in pediatric patients. ${ }^{39}$
CT angiography is invaluable not only for initial anatomic assessment of the MB, but also for preoperative planning. In patients whose right ventricular cavity is very close to the MB, for instance, special attention is needed and MICS might not be advisable.

\section{Study Limitation}

The number of patients in this study was relatively small, although top our knowledge, this is the largest pediatric case series published to date. The cohort contained selected symptomatic patients, evaluated with a careful multimodality assessment process. Postoperative invasive hemodynamic assessment was only performed in 1 patient, because the remaining patients were asymptomatic after surgery, such that the risks of repeat invasive assessment could not be justified because of no anticipated additional clinical benefit. The follow-up using the SAQ is limited to the first 6 months, not available for all subjects, and longer-term data are lacking. The SAQ was validated among older men in the Veterans Health Administration diagnosed with or undergoing evaluation for coronary artery disease. ${ }^{26}$ The SAQ has not been validated in a cohort similar to the cohort described in this report, a much younger cohort with a distinct etiology of their symptoms. Moreover, there was no control group because all of these patients were treated medically first, but eventually, medical treatment failed and surgical unroofing was elected.

\section{CONCLUSIONS}

MBs can be a cause of angina even in the pediatric population. Because of the lack of awareness of this condition, MBs can be easily overlooked, yet should be considered in the differential diagnosis of pediatric patients who present with recurrent anginal symptoms, including exertional chest pain and dyspnea. Surgical unroofing of MBs can be safely performed in pediatric patients, with or without the use of cardiopulmonary bypass. The surgery can also be performed using minimally invasive techniques. In symptomatic patients in whom physiologic significance of a bridge is established, unroofing can provide relief of symptoms refractory to medical therapy.

\section{Webcast}

You can watch a Webcast of this AATS meeting presentation by going to: https://aats.blob.core.windows.net/ media/17AM/2017-05-03/RM306/05-03-17_Room306_0850_ Maeda.mp4.

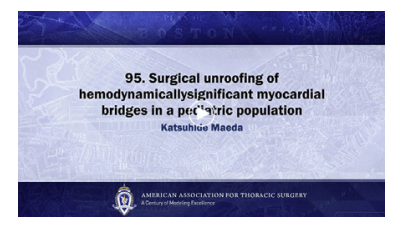




\section{Conflict of Interest Statement}

Authors have nothing to disclose with regard to commercial support.

\section{References}

1. Reyman HC. Disertatio de vasis cordis propriis. Bibl Anat. 1737;2:359-79.

2. Angelini P, Velasco JA, Flamm S. Coronary anomalies: incidence, pathophysiology, and clinical relevance. Circulation. 2002;105:2449-54.

3. Möhlenkamp S, Hort W, Ge J, Erbel R. Update on myocardial bridging. Circulation. 2002;106:2616-22.

4. Rossi L, Dander B, Nidasio GP, Arbustini E, Paris B, Vassanelli C, et al. Myocardial bridges and ischemic heart disease. Eur Heart J. 1980;1:239-45.

5. Erbel R, Ge J, Möhlenkamp S. Myocardial bridging: a congenital variant as an anatomic risk factor for myocardial infarction? Circulation. 2009;120:357-9.

6. Feld H, Guadanino V, Hollander G, Greengart A, Lichstein E, Shani J. Exerciseinduced ventricular tachycardia in association with a myocardial bridge. Chest. 1991;99:1295-6.

7. Marchionni N, Chechi T, Falai M, Margheri M, Fumagalli S. Myocardial stunning associated with a myocardial bridge. Int J Cardiol. 2002;82:65-7.

8. Cutler D, Wallace JM. Myocardial bridging in a young patient with sudden death. Clin Cardiol. 1997;20:581-3.

9. Sharma J, Hellenbrand W, Kleinman C, Mosca R. Symptomatic myocardial bridges in children: a case report with review of literature. Cardiol Young. 2011;21:490-4.

10. Noble J, Bourassa MG, Petitclerc R, Dyrda I. Myocardial bridging and milking effect of the left anterior descending coronary artery: normal variant or obstruction? Am J Cardiol. 1976;37:993-9.

11. Kramer JR, Kitazume H, Proudfit WL, Sones FM Jr. Clinical significance of isolated coronary bridges: benign and frequent condition involving the left anterior descending artery. Am Heart J. 1982;103:283-8.

12. Lin S, Tremmel JA, Yamada R, Rogers IS, Yong CM, Turcott R, et al. A novel stress echocardiography pattern for myocardial bridge with invasive structural and hemodynamic correlation. J Am Heart Assoc. 2013;2:e000097.

13. Kim PJ, Hur G, Kim SY, Namgung J, Hong SW, Kim YH, et al. Frequency of myocardial bridges and dynamic compression of epicardial coronary arteries: a comparison between computed tomography and invasive coronary angiography. Circulation. 2009;119:1408-16.

14. Ge J, Erbel R, Rupprecht HJ, et al. Comparison of intravascular ultrasound and angiography in the assessment of myocardial bridging. Circulation. 1994;89: 1725-32.

15. Gawor R, Kuśmierek J, Płachcińska A, Bieńkiewicz M, Drożdż J, Piotrowski G, et al. Myocardial perfusion GSPECT imaging in patients with myocardial bridging. J Nucl Cardiol. 2011;18:1059-65.

16. Schwarz ER, Klues HG, vom Dahl J, Klein I, Krebs W, Hanrath P. Functional, angiographic and intracoronary Doppler flow characteristics in symptomatic patients with myocardial bridging: effect of short-term intravenous beta-blocker medication. J Am Coll Cardiol. 1996;27:1637-45.

17. Escaned J, Cortés J, Flores A, Goicolea J, Alfonso F, Hernández R, et al. Importance of diastolic fractional flow reserve and dobutamine challenge in physiologic assessment of myocardial bridging. J Am Coll Cardiol. 2003;42:226-33.

18. Alessandri N, Dei Giudici A, De Angelis S, Urciuoli F, Garante MC, Di Matteo A. Efficacy of calcium channel blockers in the treatment of the myocardial bridging: a pilot study. Eur Rev Med Pharmacol Sci. 2012;16:829-34.

19. Hongo Y, Tada H, Ito K, Yasumura Y, Miyatake K, Yamagishi M. Augmentation of vessel squeezing at coronary-myocardial bridge by nitroglycerin: study by quantitative coronary angiography and intravascular ultrasound. Am Heart J. 1999; $138: 345-50$

20. Srinivasan M, Prasad A. Metal fatigue in myocardial bridges: stent fracture limits the efficacy of drug-eluting stents. J Invasive Cardiol. 2011;23:E150-2.

21. Ekeke CN, Noble S, Mazzaferri E Jr, Crestanello JA. Myocardial bridging over the left anterior descending: myotomy, bypass, or both? J Thorac Cardiovasc Surg. 2015;149:e57-8

22. Bockeria LA, Sukhanov SG, Orekhova EN, Shatakhyan MP, Korotayev DA, Sternik L. Results of coronary artery bypass grafting in myocardial bridging of left anterior descending artery. J Card Surg. 2013;28:218-21.

23. Betriu A, Tubau J, Sanz G, Magriña J, Navarro-Lopez F. Relief of angina by periarterial muscle resection of myocardial bridges. Am Heart J. 1980;100:223-6.

24. Iversen S, Hake U, Mayer E, Erbel R, Diefenbach C, Oelert H. Surgical treatment of myocardial bridging causing coronary artery obstruction. Scand J Thorac Cardiovasc Surg. 1992;26:107-11.
25. Boyd JH, Pargaonkar VS, Scoville DH, Rogers IS, Kimura T, Tanaka S, et al. surgical unroofing of hemodynamically significant left anterior descending myocardial bridges. Ann Thorac Surg. 2017;103:1443-50.

26. Spertus JA, Winder JA, Dewhurst TA, Deyo RA, Prodzinski J, McDonell M, et al Development and evaluation of the Seattle angina questionnaire: a new functional status measure for coronary artery disease. J Am Coll Cardiol. 1995;25 333-41.

27. Downar J, Williams WG, McDonald C, Wigle ED, McCrindle BW. Outcomes af ter "unroofing" of a myocardial bridge of the left anterior descending coronary artery in children with hypertrophic cardiomyopathy. Pediatr Cardiol. 2004;25: 390-3.

28. Seki H, Ramesh Janai A, Bakhtiary F, Kostelka M. Successful surgical treatment of a pronounced myocardial bridge of the left anterior descending artery with ischaemia on a two-year-old child. EuroIntervention. 2015;11:e1.

29. Yamada R, Tremmel JA, Tanaka S, Lin S, Kobayashi Y, Hollak MB, et al. Functional versus anatomic assessment of myocardial bridging by intravascular ultrasound: impact of arterial compression on proximal atherosclerotic plaque. J Am Heart Assoc. 2016;5:e01735.

30. Ishikawa Y, Akasaka Y, Akishima-Fukasawa Y, Iuchi A, Suzuki K, Uno M, et al. Histopathologic profiles of coronary atherosclerosis by myocardial bridge underlying myocardial infarction. Atherosclerosis. 2013;226:118-23.

31. Radico F, Ciccihitti V, Zimarino M, De Caterina R. Angina pectoris and myocardial ischemia in the absence of obstructive coronary artery disease: practical considerations for diagnostic tests. JACC Cardiovasc Interv. 2014;7:453-63.

32. Zoghi M, Duygu H, Nalbantgil S, Kirilmaz B, Turk U, Ozerkan F, et al. Impaired endothelial function in patients with myocardial bridge. Echocardiography. 2006;23:577-81

33. Angelini P, Uribe C, Lozano P. Differential local spasticity in myocardial bridges Tex Heart Inst J. 2012;39:384-9.

34. Hillman ND, Mavroudis C, Backer CL, Duffy CE. Supra-arterial decompression myotomy for myocardial bridging in a child. Ann Thorac Surg. 1999;68:244-6.

35. Maron BJ, Shirani J, Poliac LC, Mathenge R, Roberts WC, Mueller FO. Sudden death in young competitive athletes. Clinical, demographic, and pathological profiles. JAMA. 1996;276:199-204.

36. Eckart RE, Scoville SL, Campbell CL, Shry EA, Stajduhar KC, Potter RN, et al. Sudden death in young adults: a 25-year review of autopsies in military recruits. Ann Intern Med. 2004;141:829-34.

37. Maron BJ, Doerer JJ, Haas TS, Tierney DM, Mueller FO. Sudden deaths in young competitive athletes: analysis of 1866 deaths in the United States, 1980-2006. Circulation. 2009;119:1085-92.

38. Mery CM, Lopez KN, Molossi S, Sexson-Tejtel SK, Krishnamurthy R, McKenzie ED, et al. Decision analysis to define the optimal management of athletes with anomalous aortic origin of a coronary artery. J Thorac Cardiovasc Surg. 2016;152:1366-75.

39. Bleiziffer S, Schreiber C, Burgkart R, Regenfelder F, Kostolny M, Libera P, et al The influence of right anterolateral thoracotomy in prepubescent female patient on late breast development and on the incidence of scoliosis. $J$ Thorac Cardiovasc Surg. 2004;127:1474.

Key Words: myocardial bridge, coronary artery disease, cardiac surgery

\section{Discussion}

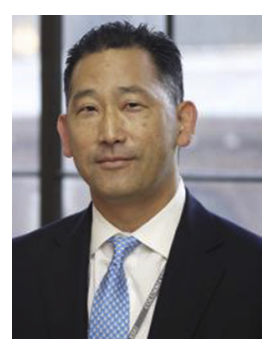

Dr Paul J. Chai (New York, NY). I want to thank you for providing me with a manuscript beforehand; I thought it was excellent, as was your presentation. Not a lot is really written or known about myocardial bridges, so it is timely to have some more information to be shared.

It is striking how similar these patients are to patients with anomalous aortic origin of the coronary artery; I thought that's quite interesting, and I think a lot of times we are still 
trying to determine how to best take care of those patients. But a lot of people, at least as a general consensus, if you have an asymptomatic left from the right would tend to be more aggressive about treating these patients.

Now, since these myocardial bridges tend to be more associated with left coronaries like the LAD, I am curious about what your thoughts are in terms of what your recommendations might be for mainly asymptomatic patients who might be incidentally diagnosed with myocardial bridges?

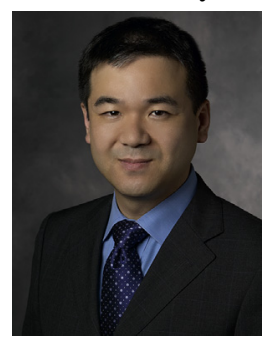

Dr Katsuhide Maeda (Stanford, Calif). First, about the anomalous coronary artery, Dr Mainwaring in our group published a paper last year about 115 surgical experiences of anomalous coronary artery, and interestingly, 7 patients had a myocardial bridge and 5 patients underwent anomalous coronary artery repair and unroofing at the same time. That means $6 \%$, but that number is probably underestimated, because we just vigorously started looking at the myocardial bridge since 2011 or so. So probably more patients have a myocardial bridge. In fact, also actually, now we have 3 patients who underwent anomalous coronary artery repair in the past and then they still had still residual symptoms. We, and now that we performed unroofing of a myocardial bridge on those patients, and then after myocardial bridge unroofing after that, it resulted in chest pain completely resolved, complete resolution, of the symptom.

About the incidental finding of the myocardial bridge by CT scan, if, it is kind of rare that we see that, because basically if we get a CT for some other reason, then we see the incidental finding of the myocardial bridge. The patient needs surgery for some other reasons anyway, we just perform the unroofing, if the myocardial bridge looks long and significant. Because unroofing itself is a very relatively straightforward safe procedure, we just perform the unroofing. But if the patient is completely asymptomatic and the patient does not need any other surgeries, basically we just carefully watch that.

Dr Chai. I think it is interesting, because now that there are more reports being published about the anomalous aortic origin, typically as a surgeon we would usually feel like the incidence of morbidity or complications from the procedure is low, so we feel confident in recommending the procedure, especially to asymptomatic patients. But now we are seeing that actually the incidence of morbidity can be quite high in these patients. So it is interesting how that is being evolved.

In your paper you actually mentioned that you excluded the patients with anomalous aortic origin of the coronary artery. You didn't talk about it in your presentation, obviously, but I am curious what your thoughts are in terms of what you found the incidence of association with anomalous aortic origin of the coronary artery was. In these patients, if you unroofed the coronary and the aorta, did you unroof the myocardial bridge as well?

Dr Maeda. Yes, we do.

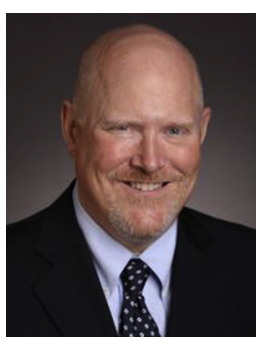

Dr James S. Tweddell (Cincinnati, Ohio). A very good study, well presented. I appreciate the use of fractional flow reserve to sort of sort out the issue here, because many of us would think that myocardial bridging was relatively benign since coronary flow is during diastole, and that's very interesting. Did you do that on every patient?

Dr Maeda. Basically all patients who still had incessant chest pain, even with medical therapy, we do this IVUS study.

Dr Tweddell. And you had 0.76; that was the FFR on average?

Dr Maeda. Usually yes, we think that FFR more than our cutoff of 0.76 is significant.

Dr Tweddell. Thank you. 